Iraqi Journal of Industrial Research (IJOIR)

Journal homepage: http://ijoir.gov.iq

\title{
Durability Investigation of Sulfur and Traditional Concrete within Aggressive Environments
}

\author{
Mohammed Jaber Al-Ani*, Jinan Abdalameer \\ Chemical and Petrochemical Research Center/ Corporation for Research and Industrial Development - Iraq
}

\section{Article information}

\section{Article history:}

Received: October, 06, 2021

Accepted: December, 04, 2021

Available online: December, 14, 2021

\section{Keywords:}

Durability,

Sulfur Concrete,

Aggressive Environment,

Compressive Strength,

Mass loss\%

\section{*Corresponding Author:}

Mohammed Jaber Al-Ani

mjpetrochemical1@gmail.com

DOI:

https://doi.org/10.53523/ijoirVol8I3ID96

\begin{abstract}
An experimental study was conducted to evaluate durability (compressive strength and mass loss \%) in the modified sulfur concrete within aggressive environments. The modified sulfur concrete was prepared by adding recycled polymeric and filler materials that showed a noticeable enhancement for modified sulfur concrete characteristics. A durability comparison between modified sulfur concrete and traditional concrete was investigated at normal and aggressive environments $(10 \%$ $\mathrm{HCl}$ and $3 \% \mathrm{NaCl})$. A cuboid shape with size $(50 \times 50 \times 50 \mathrm{~mm})$ was used in this research to investigate the durability of both modified sulfur and traditional concrete. The modified sulfur concrete characteristics revealed high stable structure than traditional due to preventing a process of crystallization of sulfur that modified with polymer and fillers. The compressive strength was $10.87-22.5 \%$ increased for modified sulfur concrete compared to the traditional concrete at the normal environment. In the aggressive environments, the modified sulfur concrete illustrated high resistance strength compared to the traditional concrete. The comparison revealed a significant impact for $10 \% \mathrm{HCl}$ and $3 \% \mathrm{NaCl}$ on the traditional concrete. The compressive strength decreased between $(88.78-96.17) \%$ for traditional concrete compared to modified sulfur concrete in $10 \% \mathrm{HCl}$ solution and $(84.25-95.06) \%$ in $3 \% \mathrm{NaCl}$ solution. Furthermore, mass loss $\%$ of the modified sulfur concrete indicated high resistance compared to the traditional concrete in both $10 \% \mathrm{HCl}$ and $3 \% \mathrm{NaCl}$ solutions.
\end{abstract}

\section{Introduction}

Traditional cement concrete has been extensively used concrete in industrial and civil construction. Increasing the demand for traditional cement production was due to changes in lifestyle and urbanization. Additionally, population growth creates new infrastructure needs that can supply people's requirements, thus escalating the order to consume more cement amounts. However, traditional cement concrete has a short life cycle against aggressive environments such as acidic and alkaline environments. On the other hand, the cement production plants are classified as one of the most impact plants on the environment, which the cement plants help emit $7 \%$ of the carbon dioxide to the atmosphere. Consequently, reducing the amount of cement consumption and improving the durability and stability of concrete have attracted more attention to enhancing the cement by using new technology. 
The first attempt to use alternative material to cement was in 1920, which suggested sulfur as a concrete compound binder [1-3].

Elemental sulfur is a significantly essential element used in the chemical industry. The sulfur can be obtained by mining and recovering at petroleum refineries and natural gas processing plants. Currently, recovered sulfur production has been increasing globally with increase petroleum consumption. Recovered sulfur production is more than the demand for the sulfur, which the sulfur industry confronting what they can do with all sulfur produces with environmental regulations continues to increase. Most of the sulfur industry stockpiled the elemental sulfur as waste and cost the sulfur industry for storage [4].

Elemental sulfur is not toxic for humans, but sulfur can be derivate to effective materials that negatively impact human health, damage animals and the environment. Sulfur dioxide and hydrogen sulfide are the most common sulfur derivatives. The most common applications for sulfur in the industry are sulfuric acid production, agricultural chemicals (phosphoric acid and phosphate fertilizers), chemical and industrial (Hydrofluoric acid and titanium dioxide), construction industry (asphalt, corrosion resistance material, and sulfur concrete), petroleum alkylation, pulp and paper, waste management (sulfur concrete), and pharmaceutical industry. One of the main objectives for the present study is waste management for sulfur in the chemical industry and recycled to use in the construction industry in the form of sulfur concrete (SC). There is several Sulfur polymer concrete (SPC), also called modified sulfur concrete (MSC), which mixes local materials with cement for more durable properties and stability and feasibility [2], [4]-[7].

Sulfur concrete (SC) is highly durable to replace construction materials, especially traditional cement. SC has revealed high resistance against harsh environments like acid and salt environments compared to traditional cement. Additionally, SC has several useful characteristics than traditional cement, such as compressive, tensile, and flexural strength, and exhibits low absorption and permeability for water [3], [7]-[9].

There are many trails of concrete rated on using the waste product to add it to construction materials. In the past decades, several research were debated reducing energy and carbon dioxide emission from raw construction materials. The majority of studies were derived to minimize the environmental impacts by replacing raw materials with waste materials $[1,3,10]$.

Sulfur concrete is one of the most significant technologies that using sulfur as a raw material in construction. Sulfur concrete has numerous advantages compared to traditional concrete. The advantages are fast curing, waste management, the possibility of recycling, quick setting time, high resistance to acid and radiation, low electrical thermal conductivity, low absorption, and low permeability $[6-8,11,12]$. Elemental has inherently numerous numbers of various effective modification because of high ability of its atoms to bond with other atoms [7, 8, 11, 13-15].

In the past, several works investigated the impact of sulfur concrete on the environment. The prime findings were the sulfur concrete was adequately safe for the environment. It is still a big deal to do more exploration due to this material is environmentally friendly $[16,17]$.

In fact, sulfur has been used as a binder in composite construction material. Sulfur cement displayed a considerable improvement for durability and stability of cement. Sulfur cement exhibited high resistance to an aggressive environment, quick curing, good strength resistance, and low water permeability $[11,12,18]$. Despite, sulfur cement failed to improve the mechanical properties. Researchers have been inspired to enhance the mechanical properties of sulfur cement and overcome these drawbacks using polymers materials. Modified sulfur concrete exhibits outstanding enhancement for mechanical and durability properties of concrete [7, 19, 20]. Modified sulfur concrete is a thermoplastic material consist of aggregates, sulfur cement, and additives. Recently, modified sulfur concrete by additives like polymers have been investigated. Polymers shows a significant change in physiochemical characteristics of sulfur concrete by reducing crystallization process of sulfur [5, 13, 21]. Consequently, cause stabilization of polymer structure. Furthermore, modified sulfur concrete contributes to apply recycled waste plastic materials and managed to reduce the amount of pollution and develop durable products $[1,3]$. 
It is valuable to produce more research on sulfur concrete modification conduct to apply waste material. A major problem of traditional concrete has been contributed to $7 \%$ of carbon dioxide emission worldwide. There is still need for more research to reduce traditional cement production by using byproduct materials. Moreover, a challenging area in the field of obtaining a modification for sulfur concrete using waste materials. In addition, a few researchers have addressed the characteristics of modified sulfur concrete using different additives and fillers on the mechanical and durability properties of concrete.

This research is a preliminary attempt to broaden the current knowledge of sulfur concrete. The aim of this project to evaluate the durability of modified sulfur concrete compared to traditional concrete. Furthermore, investigate the mechanical strength for modified sulfur concrete immersed in acidic and saline environments. Meanwhile, the process applies an industrial by-product of petroleum as sulfur. In addition, waste materials (PET) were used as additives and mineral materials (fly ash) as a filler. Mechanical and durability properties are examined to identify impact of modified sulfur in the developed concrete.

\section{Experimental Procedure}

\subsection{Materials}

Essential materials have been used to prepare alternative concrete than traditional concrete as aggregate, sand, modified sulfur, and fillers. Furthermore, aggregate, sand, water, and traditional cement were applied for traditional concrete.

\subsection{Aggregate and Sand}

Aggregate with $9 \mathrm{~mm}$ size obtained by sieving locally available mixture of sand and aggregate was used. Sand with maximum grin size $1 \mathrm{~mm}$ that obtained by sieving local sand gotten from southern of Iraq.

\subsection{Sulfur}

Elemental sulfur was applied as a binder in concrete production. Elemental sulfur is widely considered to be the most important due to the high ability of its atoms to bond with other atoms. There are two different sources for sulfur to be obtained by mining as a natural source and byproduct from industrial activities such as petroleum refineries, and natural gas.

In the petroleum section, sulfur forms approximately 1-3\% of crude oil. Due to the environmental regulations that restricted the release of sulfur dioxide into the atmosphere thus, further elemental sulfur production accumulated as a waste in the refineries. Elemental sulfur acquired from Iraqi petroleum refineries was used as a binder in concrete.

\subsection{Fly Ash}

Fly ash was added as a filler to the sulfur concrete. Fly ash was chosen as a filler due to the high accumulation in the power station as waste. The characteristics of fly ash that collected from the southern power station of Iraq, as shown in Table 1.

Table (1). Fly ash characteristics (Southern power station of Iraq)

\begin{tabular}{cccc}
\hline Element & Ratio\% & Element & Ratio\% \\
\hline $\mathrm{Fe}$ & 5.26 & $\mathrm{~Pb}$ & 0.06 \\
$\mathrm{Mn}$ & 0.45 & $\mathrm{Cu}$ & 1.17 \\
$\mathrm{Zn}$ & 1.74 & $\mathrm{Si}$ & 0.22 \\
$\mathrm{Mo}$ & 0.5 & $\mathrm{Zr}$ & 0.46 \\
$\mathrm{~V}$ & 7.15 & $\mathrm{Ni}$ & 2.03 \\
\hline
\end{tabular}

\subsection{Mixing and Casting}

The key parameter to have a good sulfur concrete mixture is controlling the temperature during mixing and casting. The temperature of mixtures is $130^{\circ} \mathrm{c}$ with variation allowances $\pm 5^{\circ} \mathrm{c}$. 


\subsection{Preparation}

The most important steps that need to be prepared before start mixing as below:

$>$ Heating fly ash, aggregate, and sand before mixing them at 170 to $200^{\circ} \mathrm{c}$ for at least $2 \mathrm{hrs}$.

$>$ Heating sulfur with polymer to at $130-140^{\circ} \mathrm{c}$ with mixing.

$>$ Preheating moulds to mixing temperature.

\subsection{Mixing and Procedure}

$>$ Add the preheated fly ash to the melted sulfur at controlled temperature between $130-140^{\circ} \mathrm{c}$ with mixing for 30 mins.

$>$ Add the modified sulfur to the mixture with mixing for 10 mins.

$>$ Cast the batch on the preheated moulds

$>$ Wait for $24 \mathrm{hrs}$ to demould the mixture.

\subsection{Mixing Proportions}

The tables below (2 and 3 ) display all mix designed in this project:

Table (2). Mix design 1.

\begin{tabular}{ccc}
\hline Materials & $\begin{array}{c}\text { Amount } \\
(\mathrm{kg})\end{array}$ & $\begin{array}{c}\text { Percentage } \\
(-)\end{array}$ \\
\hline Coarse aggregate & 9 & 45 \\
Fine aggregate & 6 & 30 \\
Cement & 3 & 15 \\
Water & 2 & 10 \\
\hline
\end{tabular}

Table (3). Mix design 1.

\begin{tabular}{ccc}
\hline Materials & $\begin{array}{c}\text { Amount } \\
(\mathrm{kg})\end{array}$ & $\begin{array}{c}\text { Percentage } \\
(-)\end{array}$ \\
\hline Sand & 6.15 & 41 \\
Fine aggregate & 6 & 40 \\
Sulfur & 1.875 & 12.5 \\
Modified sulfur & 0.18 & 1.2 \\
Fly ash & 0.795 & 5.3 \\
\hline
\end{tabular}

\section{Results and Discussion}

\subsection{Durability at Normal Environment}

Mechanical strength is defined as the ability to withstand the stress of physical forces. A compressive strength value represents the most crucial test to investigate the durability of concrete to withstand the physical forces. A (name of the instrument that measures compressive strength) was used to measure the compressive strength with different samples. Figure (1) displays the device that measures compressive strength named SEMATRON. 


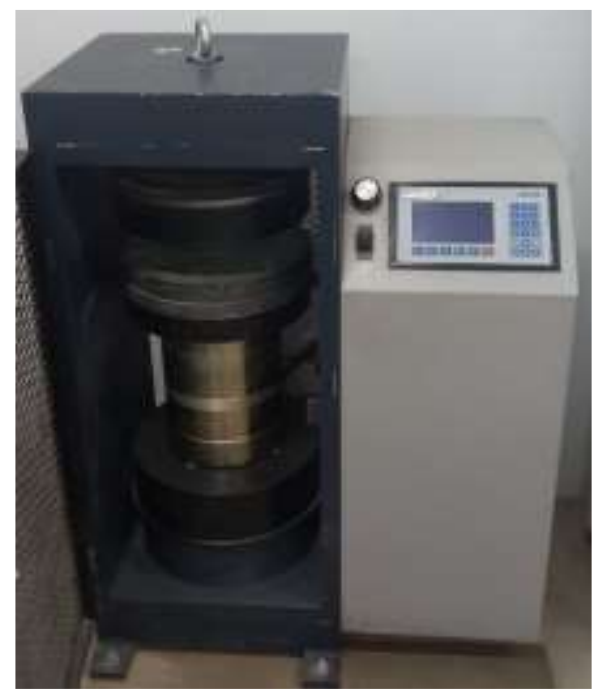

Figure (1). Photo of the device that measures compressive strength.

There was a significant difference between traditional and sulfur concrete in terms of compressive strength. It was found that the compressive strength value for sulfur concrete much higher than traditional concrete. Figure (2) provides the results obtained from experimental data of compressive strength. The results revealed minimum increase percentage of compressive strength for sulfur concrete compared to traditional concrete was $10.87 \%$ on day 21 . Whereas the maximum increase percentage was $22.5 \%$ on day 7 . The main reason for enhancing the compressive strength for sulfur concrete is the physical and chemical properties of added fillers, modified materials, and other components. On the other side, the impact of time on the compressive strength can be demonstrated, as shown in Figure (2). This study observed that time has a more negligible effect on sulfur concrete than traditional concrete. The results indicated a $6.12 \%$ increase in compressive strength for sulfur concrete after 60 days, while the $12.5 \%$ increase for traditional concrete. Thus, the curing for sulfur concrete faster than traditional concrete and reach stability quicker. The increased percentage was calculated from in equation (1):

$$
\text { Increase } \%=\left[\frac{\text { Final value }- \text { Initial value }}{\text { Initial value }}\right] \times 100
$$

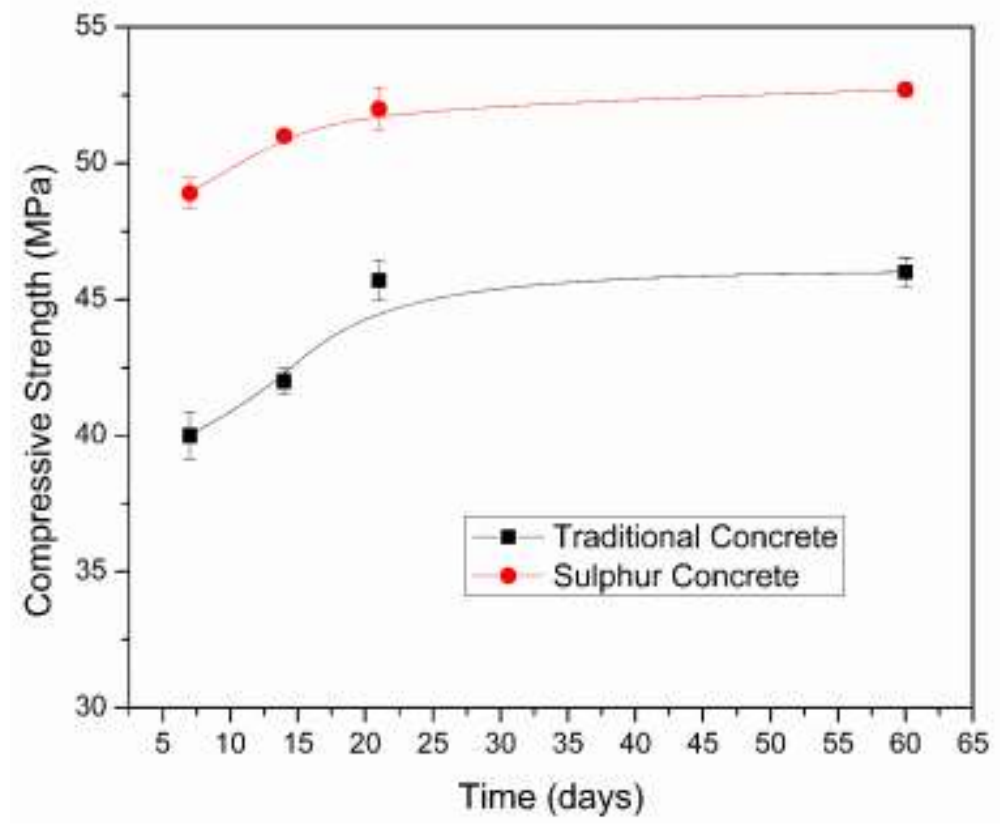

Figure (2). Compressive strength vs time at normal environment. 


\subsection{Durability in the Aggressive Environment}

It is known that there are many applications for concrete such as industry, sewer, dump, etc. The concrete might be exposed to different environments (acid or base environment) that need to be strong and highly resistant to all conditions. This study investigated the durability of traditional and sulfur concrete by immersing the concrete in an aggressive environment like 10\% $\mathrm{HCL}$ and $3 \% \mathrm{NaCl}$ within 60 days. A compressive strength has been measured, and mass loss evaluates the strong resistance and durability of concrete.

\subsection{Compressive Strength}

Figure (3) illustrates that there has been a sharp drop in the number of compressive strengths in traditional concrete after only seven days of immersion in $10 \% \mathrm{HCl}$. In contrast, sulfur concrete reflected a steady-state and stability immersion in $10 \% \mathrm{HCl}$. Additionally, time immersion in the $10 \% \mathrm{HCl}$ is a crucial factor for traditional concrete. At the same time, it is a negligible factor for sulfur concrete, which is considered an advantage to obtain high strength quickly. To sum up, sulfur concrete was higher strength resistance compared to traditional concrete. Sulfur concrete is recommended to use in industrial sites and acidic and saline environments.

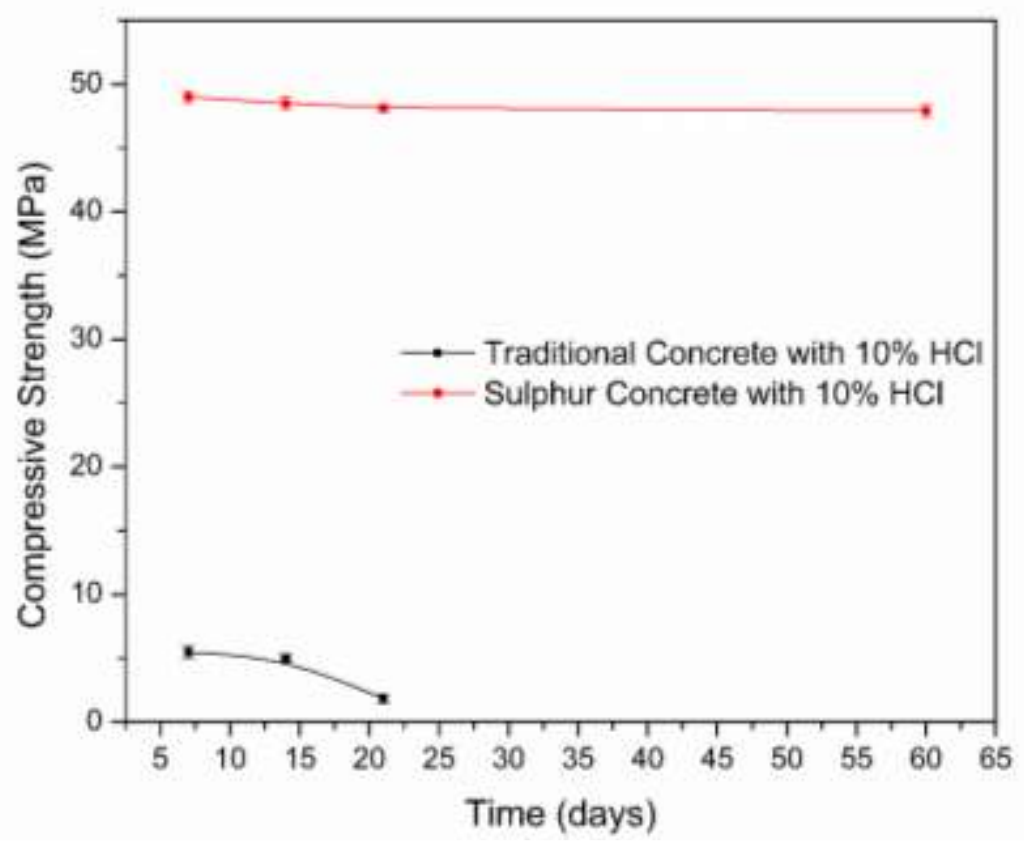

Figure (3). Compressive strength vs time immersed in $10 \% \mathrm{HCl}$.

\subsection{Mass Loss Percentage}

It is also worth noting that mass loss is significantly more frequent in investigating the stability of concrete in aggressive environments. Traditionally, mass loss has been assessed by measuring the initial and final weight after specific immersion days. Mass loss \% was calculated according to equation (2) as shown below:

$$
\text { Mass Loss }(\%)=\left[\frac{\text { Initial Weight }- \text { Final Weight }}{\text { Initial Weight }}\right] \times 100
$$

The data in Figure (4) demonstrated that the traditional concrete reported significantly more mass loss\% than the sulfur concrete. The findings of this study observed that the mass loss $\%$ for traditional concrete noticeably increased compared with sulfur concrete. In contrast, sulfur concrete displayed high stability and mass loss less influences by the $10 \% \mathrm{HCl}$ environment. The minimum mass loss $\%$ between sulfur and traditional concrete was $8 \%$ after only 7 days, while the maximum was $21 \%$ after 60 days. Furthermore, the effect of time considerably indicated on mass loss $\%$ within traditional concrete in $10 \% \mathrm{HCl}$. The maximum mass loss $\%$ was found approximately $75 \%$ between days 21 and 60 . To be concluded, sulfur concrete revealed a high resistance in $10 \%$ $\mathrm{HCl}$ compared to traditional concrete, making the sulfur concrete dominant in acidic environments. 


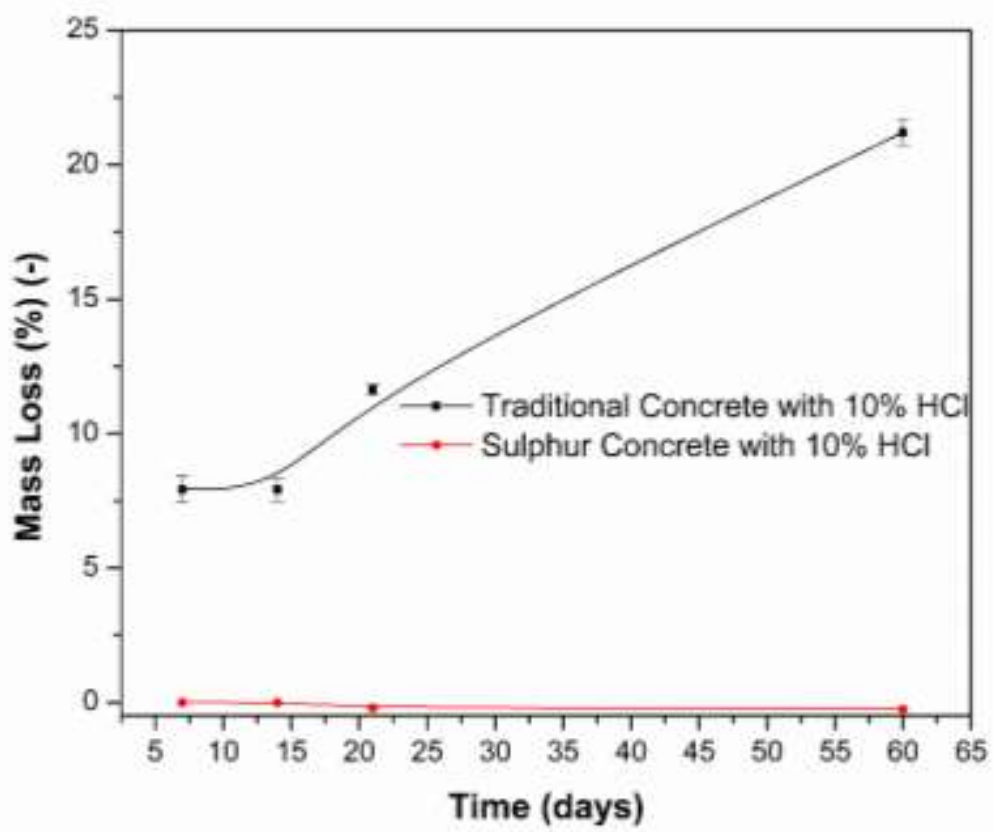

Figure (4). Mass loss \% vs time immersed in $10 \% \mathrm{HCl}$.

\subsection{Immersion in $3 \% \mathrm{NaCl}$}

The durability of traditional and sulfur concrete in saline environments was assessed within traditional and sulfur concrete immersion in $3 \% \mathrm{NaCl}$ for 60 days. Compressive strength and mass loss $\%$ were used to test the durability for both types of concretes.

\subsection{Compressive Strength}

Other observations suggest that the compressive strength test demonstrates the concrete resistance forward the saline environments. The findings detected that the compressive strength fairly stable for sulfur concrete immersed for 60 days in $3 \% \mathrm{NaCl}$. Meanwhile, the traditional concrete revealed a sharp decrease in compressed strength immersed for 60 days in 3\% NaCl. Figure (5) shows a considerable improvement in resistance for sulfur concrete compared to the traditional concrete reached $444 \%$. In addition, time was a crucial factor with traditional concrete and ineffective with sulfur concrete, as seen in Figure (5). To conclude, the sulfur concrete is more resistant and own high stability with the time that gives the dominancy to use in the saline environments. 


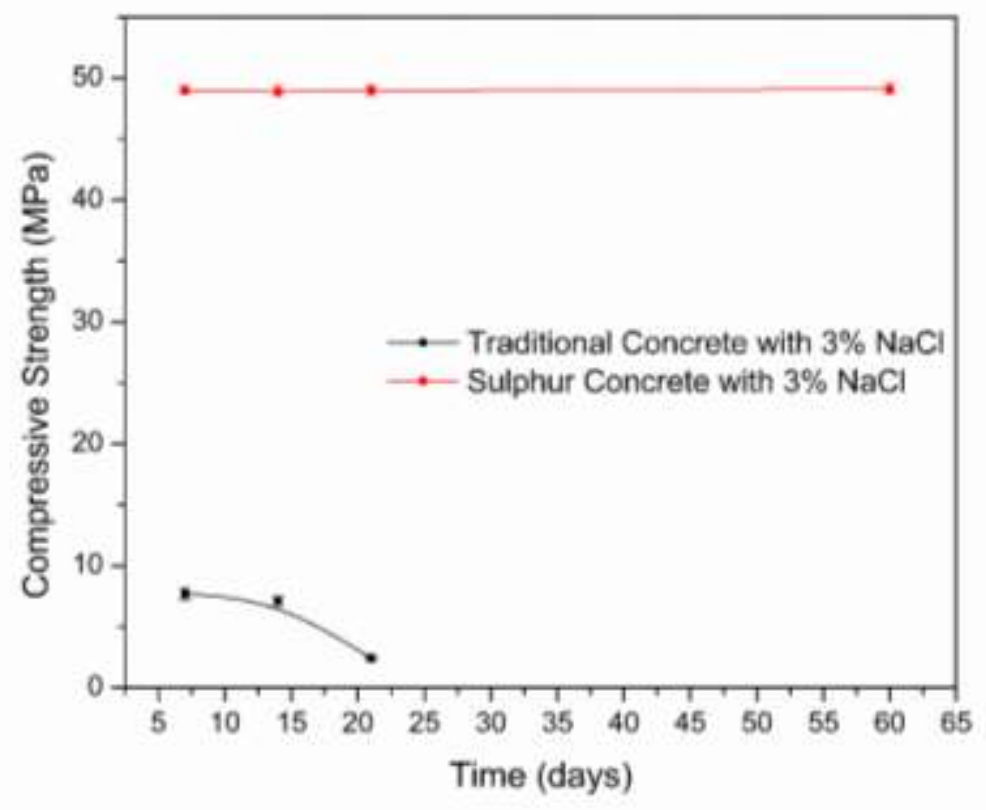

Figure (5). Compressive strength vs time immersed in 3\% $\mathrm{NaCl}$.

\subsection{Mass Loss}

Figure (6) displays the experimental data on mass loss \% for traditional and sulfur concrete in saline environments. It can be seen from the data in Figure (5) that the traditional concrete reported significantly more mass loss \% than the sulfur concrete. The difference in mass loss percentage between the two concretes was reached approximately 66.7 to $88.23 \%$. Strong evidence of sulfur concrete was highlighted to reduce mass loss \% immersed in $3 \% \mathrm{NaCl}$ as shown in Figure (6).

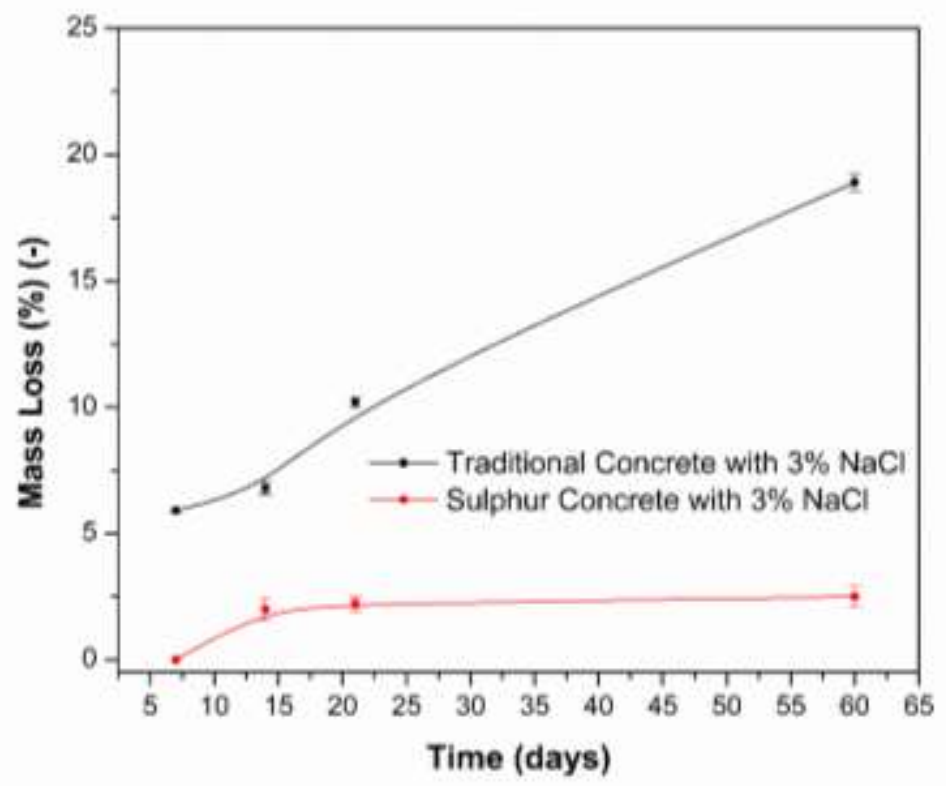

Figure (6). Mass loss \% Vs time immersed in 3\% $\mathrm{NaCl}$. 


\section{Conclusions}

Durability parameters were investigated in different types of concretes (traditional and sulfur concrete). The results revealed that sulfur concrete plays a significant role in the resistance strength in aggressive environments. Furthermore, the sulfur concrete clearly impacted the compressive strength and mass loss percentage in acidic and saline environments. Furthermore, a considerable effect for the time on the traditional concrete is displayed in this study. The main finding can be concluded as follow:

1. The sulfur concrete displayed a high efficiency using recycled sulfur elements, polymers as modifier, and filler materials. The sulfur concrete technique is promised technique to apply in aggressive environments, and it is a friendly technique that uses recycled materials.

2. The impact of polymer and fly ash on the resistance strength was significantly observed. There is a considerable increase in the magnitude of sulfur concrete compared to traditional concrete, while a noticeable reduction in the mass loss percentage for sulfur concrete compared to the traditional concrete.

3. The time influenced significantly with the traditional concrete on the resistance strength. Compared to traditional concrete, the high magnitude for compressive strength to the sulfur concrete displayed a considerable enhancement in the resistance strength.

According to the findings of the present work, additional investigation on the types of polymer characteristics needs to be developed, which will help better understand the sulfur concrete. Furthermore, study the effects of adding different fillers and aggregate size on the chemical and mechanical strength using sustainable materials is strongly recommended for extended the basic information.

\section{References}

[1] M. Lewandowski and R. Kotynia, "Assessment of sulfur concrete properties for use in civil engineering," MATEC Web Conf., vol. 219, pp. 1-15, 2018.

[2] M. Dugarte, G. Martinez-Arguelles, and J. Torres, "Experimental evaluation of modified sulfur concrete for achieving sustainability in industry applications," Sustain., vol. 11, no. 1, pp. 1-16, 2018.

[3] M. Sandanayake, Y. Bouras, R. Haigh, and Z. Vrcelj, "Current sustainable trends of using waste materials in concrete-a decade review," Sustain., vol. 12, no. 22, pp. 1-38, 2020.

[4] A. M. O Mohamed, M. M. El Gamal, and A.-M. Onsy, SULFUR CONCRETE FOR THE CONSTRUCTION INDUSTRY A Sustainable Development Approach Library of Congress Cataloging-in-Publication Data, vol. 1. 2010.

[5] J. Moon, P. D. Kalb, L. Milian, and P. A. Northrup, "Characterization of a sustainable sulfur polymer concrete using activated fillers," Cem. Concr. Compos., vol. 67, no. March, pp. 20-29, 2016.

[6] S. Al-Otaibi, A. Al-Aibani, S. Al-Bahar, M. Abdulsalam, and S. Al-Fadala, "Potential for producing concrete blocks using sulphur polymeric concrete in Kuwait," J. King Saud Univ. - Eng. Sci., vol. 31, no. 4, pp. 327$331,2019$.

[7] J. J. Fontana et al., "Guide for Mixing and Placing Sulfur Concrete in Construction," vol. 93, no. Reapproved, pp. 1-12, 1998.

[8] R. Fediuk et al., "A critical review on the properties and applications of sulfur-based concrete," Materials (Basel)., vol. 13, no. 21, pp. 1-23, 2020.

[9] J. G. G. Maldonado, D. Bastoul, S. Baig, M. Roustan, and G. Hébrard, "Effect of solid characteristics on hydrodynamic and mass transfer in a fixed bed reactor operating in co-current gas-liquid up flow," Chem. Eng. Process. Process Intensif., vol. 47, no. 8, pp. 1190-1200, 2008.

[10] C. C. Wang, H. Y. Wang, and C. Huang, "Predictive models of hardened mechanical properties of waste LCD glass concrete," Comput. Concr., vol. 14, no. 5, pp. 577-597, 2014.

[11] M. M. Vlahovic, S. P. Martinovic, T. D. Boljanac, P. B. Jovanic, and T. D. Volkov-Husovic, "Durability of sulfur concrete in various aggressive environments," Constr. Build. Mater., vol. 25, no. 10, pp. 3926-3934, 2011.

[12] M. M. Vlahović, M. M. Savić, S. P. Martinović, T. D. Boljanac, and T. D. Volkov-Husović, "Use of image analysis for durability testing of sulfur concrete and Portland cement concrete," Mater. Des., vol. 34, pp. 346354, 2012.

[13] A. M. O. Mohamed and M. El Gamal, "Hydro-mechanical behavior of a newly developed sulfur polymer 
concrete," Cem. Concr. Compos., vol. 31, no. 3, pp. 186-194, 2009.

[14] M. Dehestani, E. Teimortashlu, M. Molaei, M. Ghomian, S. Firoozi, and S. Aghili, "Experimental data on compressive strength and durability of sulfur concrete modified by styrene and bitumen," Data Br., vol. 13, pp. 137-144, 2017.

[15] C. Yang, X. Lv, X. Tian, Y. Wang, and S. Komarneni, "An investigation on the use of electrolytic manganese residue as filler in sulfur concrete," Constr. Build. Mater., vol. 73, pp. 305-310, 2014.

[16] P. Epstein and J. Selber, "Oil: A Life Cycle Analysis of Its Health and Environmental Impacts," Cent. Heal. Glob. Environ. Harvard Med. Sch., pp. 1-73, 2002.

[17] P. Kokayeff, S. Zink, and P. Roxas, Hydrotreating in petroleum processing, vol. 1. 2015.

[18] M. Shin, K. Kim, S. W. Gwon, and S. Cha, "Durability of sustainable sulfur concrete with fly ash and recycled aggregate against chemical and weathering environments," Constr. Build. Mater., vol. 69, pp. 167-176, 2014.

[19] K. Kyuhun, U. Infrastructure, and E. Program, "Mechanical Properties of Sulfur Concrete Mechanical Properties of Sulfur," 2013.

[20] R. E. Loov, A. H. Vroom, and M. A. Ward, "Sulfur Concrete - a New Construction Material.," J Prestress. Concr Inst, vol. 19, no. 1, pp. 86-95, 1974.

[21] W. C. McBee and H. H. Weber, "Sulfur polymer cement concrete," Proc. 12th Annu. Dep. Energy Low-Level Waste Manag. Conf. CONF-9008119, Natl. Low-Level Waste Manag. Progr., pp. 126-141, 1990. 